\title{
PODERÁ A CIÊNCIA COGNITIVA EXPLICAR OS ASPECTOS QUALITATIVOS DE NOSSOS ESTADOS MENTAIS? ${ }^{1}$
}

\author{
André Rosolem Sant'Anna ${ }^{2}$
}

\section{RESUMO}

Neste artigo, argumentarei que dois argumentos famosos que pretendem mostrar a impossibilidade de uma abordagem científica dos aspectos qualitativos de nossos estados mentais não conseguem sustentar essa conclusão. Para isso, primeiro apresento uma definição geral de Ciência Cognitiva, atentando para seu caráter interdisciplinar. Em um segundo momento, faço algumas considerações teóricas e metodológicas sobre como uma investigação interdisciplinar acerca da mente pode ser dada dentro do que chamo de Ciência Cognitiva. Por fim, tento mostrar que as dificuldades apresentadas na primeira parte do texto podem ser superadas por uma investigação interdisciplinar da mente baseada nos pressupostos aqui delineados.

Palavras-chaves: qualia, ciência cognitiva, materialismo.

\begin{abstract}
In this paper, I argue that two famous arguments that were designed to show that a scientific approach to qualia is not possible do not succeed. I first present a general definition of what I understand by Cognitive Science focusing on its interdisciplinary approach. After that, I spell out some theoretical and methodological considerations about how one may proceed in order to approach the mind from an interdisciplinary perspective. I finish the paper by showing that the difficulties raised in the first part of the paper can be surpassed by approaching qualia in the interdisciplinary framework outlined here.
\end{abstract}

Keywords: qualia, cognitive science, materialism.

\footnotetext{
${ }^{1}$ Gostaria de agradecer a Max Rogério Vicentini e Patrícia Coradim Sita pelos comentários e discussões acerca do texto.

${ }^{2}$ Graduando em Filosofia pela Universidade Estadual de Maringá - UEM 


\section{INTRODUÇÃO}

Um tema muito debatido nas últimas décadas diz respeito à possibilidade da explicação dos aspectos qualitativos de nossos estados mentais pela ciência. De um modo mais específico, questiona-se sobre a possibilidade de uma explicação em termos puramente físicos de estados mentais com um caráter subjetivo, tais como a sensação que temos ao experimentar algo doce ou a dor que temos ao espetarmos o dedo em uma agulha.

Neste artigo argumentarei que dois argumentos muito discutidos na literatura em filosofia da mente que pretendem explicitar esta dificuldade não nos fornecem motivos suficientes para questionarmos a possibilidade de uma abordagem científica dos aspectos qualitativos de nossos estados mentais, o que os filósofos comumente denominam por qualia.

Primeiramente, na seção I, apresentarei uma breve caracterização da Ciência Cognitiva, um esforço interdisciplinar destinado ao estudo da mente. Após isso, apresentarei uma discussão sobre a natureza metafísica dos qualia e delinearei os argumentos da Mary, a supercientista, formulado por Frank Jackson (1982), e o argumento do morcego, formulado por Thomas Nagel (1974), para tentar mostrar como os qualia apresentam dificuldades a uma abordagem científica. Ainda nesta seção, tentarei explicitar que os argumentos de Nagel e Jackson estão intimamente ligados à concepção metafísica dos qualia apresentada na seção I, o que será essencial para a nossa discussão na seção III.

Já na seção II, tentarei apresentar alguns aspectos metodológicos gerais que podem servir de norte para a pesquisa na Ciência Cognitiva. Com esta caracterização em mãos, argumentarei, na seção III, que os argumentos de Jackson e Nagel não são suficientes para duvidarmos da possibilidade de uma abordagem científica dos qualia. 


\section{A ciência cognitiva e os aspectos qualitativos de nossos estados mentais}

\section{O que é a ciência cognitiva?}

A mente, como objeto da ciência, é investigada por diferentes áreas do conhecimento. Adotando metodologias e perspectivas distintas sobre o estudo da mente, alguns cientistas, no final da década de 1940 e no início da década de 1950, perceberam que a comunicação entre estas diversas perspectivas era muito promissora $^{3}$.

Da década de 1950 aos dias atuais, a colaboração interdisciplinar entre pesquisadores das mais diversas áreas como inteligência artificial, psicologia, filosofia, neurociência, biologia, antropologia, etc. vem se tornando mais sólida, de tal modo que a esta tentativa de se integrar sistematicamente o estudo da mente foi dado o nome de Ciência Cognitiva.

A Ciência Cognitiva não constitui uma disciplina própria e independente com metodologias e objetos de investigações próprios. Ainda não é muito claro se existe uma disciplina central na Ciência Cognitiva ou até mesmo se o surgimento de uma nova área de investigação independente com o nome de Ciência Cognitiva é possível, mas a colaboração entre pesquisadores a partir desta perspectiva interdisciplinar vem se mostrando frutífera ${ }^{4}$. Nesse sentido, considerar os aspectos qualitativos de nossos estados mentais sob a ótica da Ciência Cognitiva parece uma tarefa razoável se queremos de fato investigar os primeiros cientificamente.

Desta breve apresentação da Ciência Cognitiva, um aspecto extremamente importante para os nossos propósitos neste artigo é o caráter interdisciplinar da investigação acerca da mente. Veremos, na seção III, que a integração das diversas áreas que compõem a Ciência

\footnotetext{
${ }^{3}$ Ver GARDNER (1987).

${ }^{4}$ Ver KOLAK, et. al (2006) e STILLINGS, et. al (1995). 
Cognitiva é um aspecto essencial para compreendermos como podemos visionar uma explicação científica dos qualia. Isso se dá, em parte, porque muitas das discussões acerca da possibilidade de uma explicação científica dos qualia se restringe apenas ao domínio de uma única disciplina, a psicologia, o que ignora o caráter plural da Ciência Cognitiva. Nesse sentido, para melhor compreendermos a discussão nas próximas seções, é importante termos em mente o caráter interdisciplinar da Ciência Cognitiva ${ }^{5}$.

\section{O que são os qualia?}

Grande parte dos estados mentais aos quais comumente estamos sujeitos nas diversas situações do nosso dia a dia possuem um aspecto qualitativo. Casos como experimentar uma dor ao espetar o dedo com uma agulha, sentir a doçura do mel ou ter a experiência de vermelho ao olhar para uma maçã são casos paradigmáticos dos aspectos qualitativos de nossos estados mentais. Em uma definição mais formal, conforme sugere Dennett (1988), podemos caracterizar os qualia a partir de três pontos essenciais: (i) os qualia são propriedades intrínsecas; (ii) os qualia são propriedades inefáveis ou essencialmente subjetivas; e (iii) os qualia são propriedades brutas ou monádicas. Resumidamente, podemos dizer que a ontologia dos qualia se define pela seguinte sentença: aspectos qualitativos de nossos estados mentais são propriedades intrínsecas às nossas experiências, sendo elas inefáveis e essencialmente monádicas. É com essa definição que estaremos preocupados daqui em diante ${ }^{6}$.

A definição ontológica dos qualia que consideramos aqui parece descrever com certa precisão o modo em que concebemos nossas experiências conscientes. Essa definição,

\footnotetext{
${ }^{5}$ Um questionamento que pode surgir nesse ponto diz respeito à escolha do termo "Ciência Cognitiva", no singular, em detrimento do termo no plural. O motivo pelo qual optei pelo primeiro caso é que, embora estejamos falando de diversas ciências, a Ciência Cognitiva, tal como a entendo aqui, não se reduz à atividade de nenhuma dessas ciências particulares. Assim, ainda que possamos falar de várias ciências cognitivas, quero enfatizar com o termo justamente os benefícios que resultam da colaboração dessas ciências. Além disso, a opção pelo termo no singular deixa em aberto a possibilidade da criação de um campo autônomo de investigação chamado "Ciência Cognitiva", campo que não se reduz a nenhuma de suas disciplinas componentes. Em resumo, a opção pelo termo no singular se justifica na medida em que pretendo enfatizar um aspecto que não se reduz à particularidade de nenhuma das ciências que contribuem para as investigações da Ciência Cognitiva, respeitando assim as perspectivas futuras de autonomia dessa disciplina.

${ }^{6}$ Ver DENNETT (1988) para uma descrição mais detalhadas dessas características.
} 
todavia, aponta para sérias dificuldades na tradição materialista assumida pelas ciências "hard”. Isso se dá principalmente porque, ao tentarmos estudar nossos estados mentais a partir da análise do cérebro, a ontologia trazida pelos qualia parece não se adequar às descrições aduzidas pela neurociência. Filósofos contemporâneos como Thomas Nagel (1974) e Frank Jackson $(1982,1986)$ propõem experiências de pensamento que explicitam essa discrepância entre ontologia do mundo físico e ontologia do mundo mental.

Consideremos, primeiramente, o caso de Nagel. Em seu artigo Como é ser um morcego? (1973), Nagel argumenta que uma ciência guiada por princípios objetivos não pode em princípio explicar de modo satisfatório o fenômeno da consciência ${ }^{7}$. $\mathrm{O}$ argumento de Nagel torna-se claro no contexto de uma experiência de pensamento proposta por ele: imagine que saibamos, de modo preciso e completo, tudo o que se há para saber sobre o sistema nervoso de um morcego. Dado que morcegos, adaptados a ambientes com baixa luminosidade, se localizam espacialmente através do som, isto é, o que se denomina por ecolocalização, seguir-se-ia daí que um conhecimento pleno de seu sistema nervoso deveria nos permitir saber como é se localizar através do som. Este tipo de conclusão, no entanto, tem um alto grau de contraintuitividade. Parece impossível dizer que, ainda que eu conheça todos os fatos sobre o sistema nervoso de um morcego, eu possa saber como é me localizar espacialmente através do som.

Jackson $(1982,1986)$ apresenta um argumento similar. Ele pede que imaginemos o caso de Mary, uma supercientista que vive desde os seus primeiros dias dentro de um quarto do qual não pode sair. A organização do quarto de Mary é tal que ela só pode ver objetos em preto e branco. Jackson pede-nos então para considerarmos o fato de Mary, sendo uma brilhante cientista, conhecer tudo o que se há para se conhecer do mundo físico. Note que Mary, sabendo tudo sobre o mundo físico, sabe precisamente o que ocorre no cérebro de uma pessoa quando esta está olhando para um objeto vermelho. Agora imagine que Mary seja, por algum motivo, liberada de seu quarto: teria ela um novo tipo de conhecimento quando colocada frente a objetos coloridos, mais precisamente, frente a uma maçã? Isto é, Mary teria uma nova experiência ao experimentar o vermelho da maçã?

\footnotetext{
${ }^{7}$ Uso "consciência" aqui no sentido amplo do termo, isto é, no sentido em que se aplica a outras espécies além do homem. Um dos pontos principais de Nagel (1974) é explicitar que a nossa constituição cognitiva nos impediria de termos uma compreensão efetiva da mente de animais filogeneticamente distantes de nós.
} 
Esses argumentos explicitam de forma clara as dificuldades impostas pelos qualia a um quadro teórico que assume o materialismo como ontologia básica. Para resumir o nosso ponto, parece que um estudo objetivo das propriedades físicas do mundo não nos permite conhecer tudo o que se há para conhecer das nossas experiências conscientes.

\section{O problema dos qualia}

O problema dos qualia constitui um dos tópicos centrais de discussões na literatura da filosofia da mente. Naturalmente, se a ciência pretende explicar a mente de forma efetiva, é preciso que olhemos atentamente para o caso dos qualia. O problema, tal como o apresentei até aqui, parece residir em um abismo ontológico existente entre o modo em que concebemos nossas experiências conscientes, nomeadamente um modo subjetivo, e o modo em que se formulam as explicações na ciência, ou seja, um modo objetivo.

Essa oposição entre "objetivo" e "subjetivo" aponta para um problema ontológico em relação à possibilidade de se explicar os qualia cientificamente. Em outras palavras, de que modo poderíamos explicar propriedades que são essencialmente subjetivas em termos objetivos? Tal proposta parece estar fadada ao fracasso.

Há, neste ponto, duas possíveis soluções para o problema: ou assumimos que os qualia são propriedades que não se reduzem ao físico, violando assim uma das principais intuições da ciência contemporânea, isto é, aquela segundo a qual uma explicação para um fenômeno deve ser dada em termos puramente físicos, ou então procuramos estabelecer algum quadro teórico que nos permita fazer esta conciliação.

A minha proposta neste trabalho é proporcionar uma defesa deste segundo ponto. Para melhor compreender esse posicionamento, considere a concepção ontológica dos qualia apresentada acima e os argumentos apresentados contra o materialismo na primeira parte desta seção. Jackson (1982) e Nagel (1974) parecem estar concernidos com uma concepção de qualia que assume as três características que mencionamos acima. No caso de Jackson, isso fica evidente na medida em que consideramos que Mary não sabe o que ter a sensação do vermelho justamente porque tal sensação é: (a) intrínseca, já que não pode ser conhecida por algo mais básico a não ser pela própria sensação, (b) subjetiva, já que nenhuma descrição do 
ponto de vista objetivo pode exaurir a natureza do fenômeno, e (c) monádica, já que, como em (a), os qualia não podem ser caracterizados em termos mais básicos do que eles próprios ${ }^{8}$.

Já no caso de Nagel, tal assunção metafísica fica evidente na medida em que: (a) qualquer descrição objetiva do sistema nervoso em termos mais básicos do que os qualia de um morcego não nos permite conhecer a sensação subjetiva de como é ser um morcego, e (b) esta sensação só pode ser conhecida apenas a partir de um ponto de vista, isto é, o ponto de vista do morcego, o que torna esta sensação intrínseca às experiências dos morcegos.

Se considerarmos estas objeções sobre a caracterização metafísica de qualia que apresentei até aqui, certamente os qualia apresentariam sérios problemas para uma abordagem científica da mente. Podemos observar, no entanto, que tal caracterização dos qualia expressa somente a concepção metafísica do fenômeno a partir de um ponto de vista específico, a saber, o ponto de vista do sujeito.

Em seu livro Conscioussness and Content (1969), Daniel Dennett denomina as classificações feitas na perspectiva do sujeito de classificações do nível pessoal. De acordo com Dennett, no entanto, a investigação acerca dos fenômenos mentais não precisa se restringir a uma análise feita no nível pessoal. Podemos, por outro lado, adotar perspectivas de análise que se situam em níveis abaixo do nível pessoal, perspectiva que Dennett denomina de perspectiva do nivel sub-pessoal. De um modo geral, as investigações empreendidas pela neurociência seriam características das investigações dadas nesse nível, já que a proposta desta última disciplina é a de investigar estados mentais através da investigação de operações mais básicas ocorrentes no cérebro.

Neste ponto, é razoável questionar se a concepção metafísica dos qualia dada no nível pessoal é uma concepção adequada para guiar as investigações no nível sub-pessoal. Comecemos, portanto, relembrando os aspectos básicos da ontologia dos qualia. Novamente, os qualia, tal como os definimos acima são: (i) intrínsecos; (ii) subjetivos ou inefáveis; e (iii) monádicos. Como vimos, esta definição ontológica não parece se adequar ao que ocorre em nossos cérebros em termos objetivos.

\footnotetext{
${ }^{8}$ Note que, embora (a) e (c) possam parecer a mesma tese, a primeira é uma tese epistemológicas, ao passo que (c) é uma tese ontológica. 
Em seu artigo Eliminative matelialism and the propositional attitudes (1981), Paul Churchland sugere que os termos que usamos para nos referir aos nossos estados mentais são termos muito imprecisos para descrever satisfatoriamente a complexidade de nossas experiências conscientes. Esses termos são conhecidos por folk psychology ou psicologia de senso comum, termo cunhado por Daniel Dennett (1981). De acordo com Churchland, assumir que nossa mente seja organizada do modo como prescreve a psicologia de senso comum, isto é, uma mente detentora de crenças, desejos, intenções, qualia, etc. não descreve de modo preciso o que ocorre em nosso cérebro.

Nesse contexto, ainda nesse mesmo artigo, Churchland argumenta que a psicologia de senso comum é uma teoria que pode ser eliminada em favor de uma teoria mais precisa, tal como se observa em outros casos na história da ciência. Assim, na perspectiva de Churchland, a ontologia referente aos entes da "folk psychology" seria eventualmente eliminada com os avanços da neurociência. Em outras palavras, as três características acima não seriam mais características que descreveriam os aspectos qualitativos de nossas experiências conscientes.

Outra proposta de eliminação dos qualia dentro deste contexto de discussão é amplamente discutida por Daniel Dennett em Quining qualia (1988). Dennett apresenta várias "bombas de intuição" (intuition pumps) que pretendem minar o fundamento ontológico tradicional dos qualia.

Dennett nos mostra que falar dos qualia como propriedades intrínsecas e monádicas não faz sentido frente a algumas experiências particulares. Considere, por exemplo, o caso dos enólogos. No caso desses indivíduos, a experiência qualitativa que eles têm ao provar um determinado vinho é totalmente distinta daquela que a maioria de nós, pessoas não treinadas, temos ao experimentar o mesmo vinho. O enólogo pode dizer, com determinada precisão, qual é a composição físico-química do vinho, enquanto nós, degustadores não treinados, temos uma experiência por vezes simples, homogênea e bruta na qual, na melhor das hipóteses, podemos especular sobre o teor alcoólico do vinho.

É evidente que, neste caso, as características atribuídas aos qualia anteriormente não se aplicam ao caso do enólogo. Este último pode inferir, através da identificação de tais e tais substâncias, que o quale que ele experimenta ao tomar aquele vinho é o quale referente a uma 
determinada marca de vinho, e não a outra. Em outras palavras, o quale do enólogo não é intrínseco à sua experiência, já que ele parte de pressuposições mais básicas para então identificar aquele quale a um determinado tipo de vinho.

O mesmo pode ser dito no caso da característica (iii), isto é, a consideração de que os qualia são propriedades monádicas e brutas. Se podemos distinguir aspectos mais básicos e constituintes da experiência que temos ao beber uma taça de vinho, isso significa que essa experiência não é mais homogênea, já que se compõe agora de partes distintas. Isso fica evidente no fato de que o enólogo pode identificar a presença de diferentes substâncias no vinho.

Até o presente momento lançamos dúvida sobre as características (i) e (iii) dos qualia. O que dizer, no entanto, da característica (ii)? Parece que as nossas considerações até aqui não afetam a definição de qualia enquanto propriedades subjetivas e inefáveis, o que, em certa medida, pode ser considerado o principal aspecto de nossos estados mentais.

Quando digo que tenho uma dor de cabeça, essa dor de cabeça é somente minha no sentido em que outro indivíduo não pode sentir a minha dor de cabeça. O termo que usamos para nos referir ao quale desta dor é, nesse sentido, um termo com significação individual (e, portanto, subjetivo), uma vez que somente nós podemos senti-la. Parece evidente, entretanto, que quando temos uma dor de cabeça, por exemplo, algum tipo de reação esteja ocorrendo em nosso cérebro, caso contrário, a dor não seria aliviada quando tomamos algum tipo de analgésico. Esse tipo de reação é comum entre múltiplos sujeitos, o que, até certo ponto, justifica a nossa crença de que sentimos dores similares.

Considere, todavia, que um viajante do tempo vindo do ano 2.375 nos faça uma visita. Nesse ano, a neurociência já teria vivenciado diversas descobertas de tal modo que se tornou comum aos indivíduos daquela época dizer que as fibras- $\mathrm{C}$ em determinada região de seu cérebro estejam sendo estimuladas ao invés de dizer que eles têm uma dor de cabeça. Considere, todavia, que este viajante não conheça a história da neurociência, de tal modo que, naturalmente, ele se espante com a nossa resistência em aceitar que aquilo que denominamos por dor seja apenas estimulação de fibras-C. 
Se apresentarmos a ele o início deste texto no qual definimos nossas experiências qualitativas como subjetivas, não espantosamente o viajante iria protestar. Para ele, é perfeitamente claro que o que ele se refere por dor não é algo subjetivo: a sua dor é simplesmente o resultado da estimulação de fibras-C em seu cérebro, sendo essas estimulações perfeitamente passíveis de observação.

Como aponta Paul Churchland (1989, p. 151), o que torna uma explicação uma explicação de primeira pessoa é somente a familiaridade do idioma e a espontaneidade de resposta seguindo um esquema conceitual. Nesse sentido, não há nada que nos impeça de começar a descrever nossas experiências introspectivas ou subjetivas por termos objetivos.

\begin{abstract}
A neurociência pode parecer incapaz de nos dar uma explicação pura em "terceira pessoa" da mente, mas apenas familiaridade do idioma e a espontaneidade de respostas conceituais são requeridas para fazer uma explicação "explicação de primeira pessoa". O que faz uma "explicação de primeira pessoa" ser tal não é o conteúdo desta explicação, mas o fato de que o indivíduo comece a usar essa explicação como veículo de conceitualização espontânea da introspecção e da descrição de si mesmo. (Trad. minha) (CHURCHLAND, 1989, p. 151),
\end{abstract}

Parece ser concebível, portanto, que no caso do viajante do tempo, a descrição de seus qualia não mais seria uma descrição subjetiva, mas sim uma descrição objetiva. Isso nos mostraria, por sua vez, que o caráter subjetivo dos qualia não mais corresponde a uma propriedade essencial de nossos estados mentais, mas meramente ao modo em que denominamos estas propriedades.

\title{
II. Identidades heurísticas e teorias interfield
}

Para lidarmos com o problema dos qualia dentro da Ciência Cognitiva, algumas considerações teóricas e metodológicas são necessárias. Nesta seção, tentarei delinear esses aspectos e na próxima seção tentarei mostrar como eles podem ser aplicados no caso dos qualia.

Uma proposta de trabalho interdisciplinar que pode ser aplicado à Ciência Cognitiva pode ser identificada nas teorias de identidade heurística (TIH) de McCauley e Bechtel 
(2001). De acordo com McCauley e Bechtel (2001, p. 753), a TIH deve ser vista como a premissa e não como a conclusão de uma investigação científica. Isso quer dizer que a identidade entre estados mentais e interações neurofisiológicas no cérebro deve ter um valor heurístico para futuras investigações. Assim, contrário ao que pressupõe uma postura reducionista, a identidade de um estado mental $x$ com interações neurofisiológicas $y$ não é a consequência de uma teoria bem desenvolvida na neurociência, mas, antes, essa identificação é o que possibilitará a emergência dessa teoria neurocientífica.

Compreendamos essa última afirmação com mais precisão. McCauley e Bechtel argumentam que a identidade entre estados mentais e estados neurais não precisa ser uma identidade com precisão de detalhes (fine-grained identity). O que importa em uma identidade neural é que ela estabeleça uma agenda de pesquisa (research agenda) no sentido em que uma vez que uma área cerebral é identificada com uma função determinada, experimentos possam ser realizados com a finalidade de testar se essa identidade é uma identidade precisa ou não.

Esses experimentos, no entanto, não devem ser realizados somente no domínio de uma disciplina de investigação, o que explicita a importância do caráter interdisciplinar da Ciência Cognitiva que mencionamos na seção I. Nesse sentido, o pesquisador não deve se restringir a uma visão disjuntiva da investigação científica: a investigação acerca da mente não deve ser restringida à psicologia ou à neurociência, por exemplo. Ao contrário, a proposta que McCauley e Bechtel sustentam é tal que a integração entre os diversos domínios da investigação científica são essenciais. Tal integração é justificada na medida em que essas diversas disciplinas têm um interesse comum em um mesmo fenômeno, e, ao mesmo tempo, possuem diferentes perspectivas teóricas e metodológicas para enfrentar um problema. Essa discrepância teórica e metodológica gera diferentes experimentos em cada domínio, de tal modo que resultados e experimentos de um domínio podem iluminar dificuldades em outros domínios. Com essas considerações em mente, o questionamento que poderíamos nos colocar neste ponto é o seguinte: qual é a natureza de uma teoria resultante dessa proposta interdisciplinar de investigação?

A resposta para esse problema pode ser encontrada em um artigo de Darden e Maull (1977). Em outras palavras, o tipo de teoria que emerge desse tipo de investigação é chamada 
por Darden e Maull de teorias "interfield" . De acordo com Darden e Maull, as teorias "interfield" nascem quando "duas áreas de investigação compartilham de interesses em explicar aspectos diferentes de um mesmo fenômeno" (1977, p. 133). Nesse sentido, diferentes aspectos das atividades mentais poderiam ser investigadas por diferentes áreas de investigação seguindo os pressupostos de uma teoria "interfield”. Como podemos observar, as teorias "interfield" representariam uma perspectiva teórica interessante para integrar o esforço interdisciplinar da Ciência Cognitiva.

Como Darden e Maull enfatizam, o tipo de abordagem proporcionado pelas teorias "interfield" permitem ao investigador responder questões que parecem desconcertantes ou muito difíceis usando os conceitos e técnicas de somente uma área de investigação. Elas mencionam, por exemplo, a contribuição mútua dada por diferentes áreas como a citologia e a genética ao desenvolver uma teoria mais detalhada e precisa dos cromossomos. Para resumir este ponto, podemos dizer que teorias "interfield" são geradas quando:

Conhecimentos de fundo [background knowledge] indicam que relações entre as áreas de investigação já existem quando estas áreas compartilham de um interesse em explicar diferentes aspectos de um mesmo fenômeno e quando questões sobre este fenômeno surgem em uma área e não podem ser resolvidos com as técnicas e conceitos desta mesma área. (Trad. minha) (DARDEN e MAULL, 1977, p. 134)

Uma pergunta razoável a se fazer aqui frente à proposta de Darden e Maull (1977) é a de como a relação entre as diversas áreas de investigação associadas com uma teoria "interfield" pode ser explicada. Em outras palavras, o que nos permite fazer a ligação entre os conceitos e assunções teóricas de uma área com as outras? Darden e Maull (1977) apresentam uma análise de como isso é possível no caso da citologia e da genética, mas nós não iremos considerar esse caso aqui. Em contrapartida, proponho que olhemos para o caso da integração entre duas áreas que são de nosso interesse primário, a psicologia e a neurociência.

\footnotetext{
${ }^{9}$ Optei por manter o termo original "interfield" por uma questão de precisão. Poder-se-ia traduzir o termo por algo semelhante a "teorias entre-áreas", mas acredito que o termo em inglês reflete de modo mais preciso o aspecto teórico que temos em vista aqui.
} 
Técnicas de radiografia como a Ressonância Magnética Funcional (fMRI) e a Tomografia por Emissão de Pósitrons (PET) são muito comuns nos dias de hoje. Um de seus diversos usos consiste em ajudar a determinar a função de determinadas regiões do cérebro. Um exemplo simples deve servir para nossos propósitos. Elementos como glicose e oxigênio são metabolizados no cérebro de acordo com a atividade de determinada região cerebral. No PET, oxigênio radioativo pode ser inserido na corrente sanguínea, de tal modo que as áreas com estes átomos poderão ser identificadas na radiografia. Em estudos de caso, uma pessoa que tem o oxigênio radioativo inserido em sua corrente sanguínea deve realizar diferentes tarefas enquanto seu cérebro está sujeito à radiografia. Uma vez que a radiografia for feita, o oxigênio radioativo será mostrado em determinadas áreas, o que seria indicativo de que tais áreas apresentaram maior atividade quando a pessoa realizou determinadas tarefas. Esse pode ser considerado um primeiro passo em direção à associação de funções a regiões do cérebro, já que podemos identificar quais regiões operam mais ativamente quando determinada tarefa é realizada.

O aspecto interessante desse primeiro passo para a identificação de funções cerebrais é que quando pedimos ao sujeito da experiência para que realize uma determinada tarefa, pedimos para ele realizar algo que é psicologicamente caracterizado. Em outras palavras, pedimos para que o sujeito realize tarefas que são caracterizadas pelos termos da folk psychology que discutimos acima. Mais especificamente, nesses experimentos o sujeito precisa descrever algo, identificar algo, decidir fazer algo, etc. Todos esses termos são termos derivados do vocabulário mental folk que usamos em nosso cotidiano. Isso demonstra que a folk psychology é importante pelo [sugir uma troca por 'ao'] menos nos processos iniciais de um estudo mais completo e preciso da funcionalidade das áreas do cérebro. Disso tudo, parece possível dizer que, de algum modo, termos da psicologia e as pesquisas em neurociência estão envolvidos ${ }^{10}$.

\section{Ciência cognitiva e o problema dos qualia}

\footnotetext{
${ }^{10}$ Mundale e Bechtel (1999) argumentam que a biologia evolutiva também é essencial neste processo de identificação. Não entrarei nos detalhes desta discussão aqui, mas, para eles, a história evolutiva é de extrema importância para determinar as funções cerebrais. 
Na última seção olhamos para os aspectos teóricos e metodológicos do modo em que a Ciência Cognitiva pode investigar os qualia. Nesta seção apresentarei um exemplo de como essa investigação se dá no plano empírico. Um exemplo de um olhar empírico mais acurado para as questões que estamos tratando aqui é dado por Kathleen Akins (1993). A proposta de Akins (1993) é a de investigar com mais detalhes os aspectos fisiológicos dos morcegos para ver se ganhamos algum conhecimento sobre a vida subjetiva desses animais na medida em que nos especializamos em sua fisiologia. Apresentarei, de modo breve, os pontos principais da proposta de Akins (1993) e então apontarei para os traços de uma integração de teorias baseada em uma teoria "interfield". Passemos, portanto, a essa discussão.

Podemos, inicialmente, perguntar sobre a função da ecolocalização, isto é, o aspecto que é enfatizado pela experiência de pensamento de Nagel (1974). Para que exatamente morcegos precisariam dela? Uma resposta razoável seria a de que, dado que morcegos vivem em locais com baixa luminosidade, seria vantajoso do ponto de vista evolutivo que eles se utilizassem de outra modalidade diferente da luz para perceber seu ambiente externo. Nesse sentido, poderíamos dizer que a ecolocalização é uma forma que a evolução encontrou para permitir que os morcegos representassem seu ambiente externo. Um problema com essa resposta, no entanto, é que outros animais que vivem em locais de baixa luminosidade não desenvolveram capacidades de representação através som, mas sim a partir da representação visual (o caso das corujas, por exemplo). Poderíamos nos questionar, neste ponto, o motivo pelo qual a evolução "fez" esta escolha no caso dos morcegos.

Este último ponto fica evidente na medida em que consideramos as diferentes propriedades físicas do som e da luz. Como descreve Akins (1993, pp. 121-23), o som, ao contrário da luz natural, não possui uma fonte de origem única e que se distribui homogeneamente entre diversos objetos de um ambiente específico. Isso faz com que o morcego precise de uma fonte homogênea e constante de som, de tal modo que a informação sonora provinda do ambiente possa ser confiável para guiar seu comportamento. Neste ponto, parece ser justificável, do ponto de vista da evolução, o fato de morcegos emitirem ondas sonoras enquanto se movimentam, já que a sua localização espacial torna-se um ponto de referência como fonte emissora de som. 
Outra característica interessante descrita por Akins (1993) é a de que a propagação de ondas sonoras depende da vibração do meio em que elas se encontram. Isso quer dizer que, além da intensidade e do comprimento de onda, o meio no qual o morcego se encontra será decisivo nas ondas em que ele produzirá para enviar ao ambiente. Em outras palavras, diferentes meios requererão diferentes sinais emitidos pelo morcego.

Uma terceira característica importante apontada por Akins (1993) é a de que ondas sonoras, ao contrário da luz, estão sujeitas a altos graus de difração e difusão. Isso indica que representações sonoras não são diretamente dadas ao morcego; ao contrário, é preciso que toda uma computação neural seja realizada para que eventuais distorções provindas da difração e da difusão das ondas sonoras sejam "corrigidas".

Um ponto importante dessa breve discussão é o de que alguns aspectos da vida de um morcego são justificados a partir de considerações que levam em conta a interação desse morcego com seu ambiente ao longo da evolução. Não há aqui, entretanto, uma descrição exata de como estes processos de fato ocorrem. Sabemos, no entanto, que os fatos acima mencionados devem moldar de algum modo o funcionamento do aparelho cognitivo de um morcego, já que estes fatos são fatos mais elementares sobre a natureza do som.

Após passar por considerações acerca da natureza do som, Akins (1993, p. 133) se dedica a uma investigação sobre as estratégias comportamentais utilizadas pelos morcegos no processo de ecolocalização, estratégias que devem, de algum modo, ser adequadas com a natureza física do som. De modo resumido, a ecolocalização tem uma função primária na caça dos morcegos, de modo que o comportamento desses morcegos pode ser caracterizado em três fases distintas: (a) a Fase de Procura; (b) a Fase de Abordagem e de Rastreamento; e (c) a Fase Terminal. Akins (1993, p. 133) as descreve da seguinte forma:

"[...] inicialmente o morcego procura por algo de interesse, como nos casos em que voa "procurando" por insetos (a Fase de Procura); então, uma vez que a preza é localizada, o morcego deve abordar o inseto e rastrear ele até que chego perto o suficiente para capturá-lo (a Fase de Abordagem e de Rastreamento); finalmente, uma vez que a preza possa ser capturada, o morcego deve, de algum modo, iniciar a abordagem final para que possa colocar o inseto em sua boca (a Fase Terminal)" (Trad. minha) (AKINS, 1993, p. 133) 
Akins (1993, pp. 134-39) descreve com precisão esse processo, mencionando inclusive sinais com freqüências distintas produzidos pelos morcegos para identificar diferentes aspectos do ambiente. Por exemplo, sinais com freqüência constante (sinais FC) trazem informações sobre a velocidade de uma preza, ao passo que sinais com freqüências modulares (FM) trazem informações sobre a localização espacial das prezas.

Esses aspectos mais detalhados não devem ser de muita importância para os nossos propósitos, por isso os deixarei de lado neste momento. $\mathrm{O}$ que devemos ter claro é que tais aspectos são aspectos que descrevem aspectos comportamentais dos morcegos. $\mathrm{Na}$ terminologia de Dennett (1969) que vimos anteriormente, poderíamos dizer que tais aspectos estão relacionados a um nível pessoal de análise, isto é, ao nível do morcego enquanto indivíduo.

Uma investigação mais aprofundada deve buscar pelos mecanismos subjacentes ao funcionamento do sistema no nível pessoal, já que uma explicação comportamental não esgota as peculiaridades do funcionamento do sistema nervoso do morcego. Este é, de fato, o próximo passo da proposta de Akins (1993). Ela aponta para o fato de que muitas áreas sensoriais no cérebro de um morcego são constituídas por "mapas" de neurônios que retratam estímulos preferidos dessas áreas. Nesse sentido, para usar o exemplo da estratégia comportamental da emissão de sinais de diferentes frequências, é possível identificar áreas no córtex auditório primário dos morcegos regiões responsáveis pelo processamento de informações relativas aos sinais FC e aos sinais FM, o que sustentaria a distinção comportamental na emissão de sinais com freqüências diferentes mencionada acima. Esses mapas de neurônios explicariam de um modo mais detalhado como a discriminação de tais sinais é possível e como os morcegos fazem o uso dessas informações.

Após uma discussão mais detalhada sobre a relação entre comportamento e funcionamento do aparelho cognitivo, Akins (1993, p. 149) sugere que um olhar atento para o cérebro do morcego nos permite perceber que as relações lá existentes tornam muito improvável que morcegos tenham representações semelhantes às representações visuais que nós temos de nosso ambiente externo. De acordo com Akins, o "loop" de informação entre input-output nos morcegos é muito curto, o que reduziria drasticamente as possibilidades de 
haver ali uma representação intermediária com semelhante complexidade às nossas representações visuais.

Essa discussão tem um caráter geral e não faz jus a todos os detalhes apresentados por Akins (1993). Entretanto, podemos observar importantes aspectos que são relevantes para a nossa discussão nas seções anteriores. Primeiro, iniciamos a discussão acerca da ecolocalização em morcegos questionando sobre qual seria a função desta capacidade. Uma hipótese inicial e coerente do ponto de vista evolutivo seria a de que ela serviria para representar o ambiente externo. Vimos, entretanto, que o som apresenta propriedades físicas distintas daquelas apresentadas pela luz, o que, de certo modo, indicaria que os morcegos teriam que empreender diferentes estratégias das apresentadas pelos animais que possuem representações visuais como representações espaciais primárias. Uma destas estratégias é a de cada indivíduo ser a fonte de emissão de sons, uma vez que não há nenhuma fonte natural de som homogênea e fixa tal como a luz. Esses fatos acerca da natureza do som nos levaram a considerar estratégias comportamentais específicas dos morcegos, como é o caso da emissão de sinais de diferentes freqüências para rastrear diferentes aspectos do ambiente.

Essas estratégias, como aponta Akins (1993), são explicadas a partir da constituição neurofisiológica dos morcegos. Essa constituição neurofisiológica, no entanto, torna pouco provável que existam representações que intermedeiem a entrada de inputs e outputs no morcego, já que a relação entre ambos é uma relação muito rápida. A partir disso, Akins (1993, p. 149) afirma que: “a função do sistema sonar dos morcegos [...] é: assegurar de modo seqüencial informações altamente filtradas que podem ser usadas de modo online para guiar o vôo do morcego", o que explicita o caráter imediato de manutenção da informação no aparelho cognitivo do morcego.

A questão em foco aqui pode ser resumida neste condicional: se os dados empíricos tornam improvável que morcegos tenham representações duradouras do ambiente que os cercam, disso poderíamos concluir que sua vida subjetiva diferiria substancialmente da nossa. Essa conclusão, embora de caráter negativo, nos permite conhecer algo sobre a vida subjetiva dos morcegos. Akins (1993, p. 147) especula que talvez não haja nada como o ponto de vista (point of view) de um morcego. Não precisamos nos ater a tal conclusão, já que, como a 
própria Akins (1993, p.154) reconhece, ainda não conhecemos o suficiente sobre o sistema nervoso de um morcego.

É evidente, no entanto, que a hipótese inicial segundo a qual a ecolocalização teria a função de representar o ambiente externo tornou-se implausível frente aos dados neurofisiológicos do morcego. Esses dados, no entanto, só puderam ser analisados adequadamente uma vez que possuíamos uma descrição adequada das estratégias comportamentais dos morcegos, estratégias que são entendidas de modo mais preciso quando consideramos o ambiente evolutivo dos morcegos e o funcionamento de seu aparelho cognitivo. Torna-se claro, neste ponto, a revisão e o aprimoramento de hipóteses em uma área de investigação pelos resultados provindos de outra área de investigação. Disso tudo, podemos observar que uma integração entre a teoria da evolução, entre os aspectos comportamentais de morcego (uma espécie de "psicologia dos morcegos") e a neurociência dos morcegos nos permite conhecer alguns aspectos importantes da vida subjetiva ou dos qualia dos morcegos, o que é de suma importância para o estudo dos qualia pela Ciência Cognitiva.

\section{Conclusão}

A conclusão dessa discussão é que não há razões para resistirmos a uma abordagem científica dos qualia. Na verdade, as dificuldades apresentadas pelos argumentos de Jackson (1982) e Nagel (1974) são dificuldades naturais uma vez que as consideramos na perspectiva do trabalho interdisciplinar da Ciência Cognitiva. Como vimos pela discussão de Akins (1993), uma compreensão interdisciplinar acerca do sistema nervoso dos morcegos permitenos conhecer algo sobre sua vida subjetiva.

O mesmo pode ser dito do caso de Mary. O fato de que Mary parece descobrir algo novo quando ela deixa seu quarto e olha para uma maçã vermelha é sustentado pelas três características tradicionais que discutimos na seção I. Para relembrarmos, estas características eram: (i) qualia são propriedades intrínsecas de nossas experiências; (ii) qualia são inefáveis ou subjetivos; e (iii) qualia são propriedades brutas ou monádicas. 
Assim, poderíamos dizer que Mary descobre algo novo quando ela vê algo vermelho porque (i) a vermelhidão (redness) é intrínseca à experiência do vermelho e deste modo só pode ser conhecida quando nós temos esta experiência; (ii) a vermelhidão é uma propriedade inefável ou subjetiva que não pode ser descoberta de um modo objetivo; e finalmente (iii) porque a vermelhidão é uma propriedade básica ou bruta que não pode ser conhecida através do conhecimento de propriedades mais básicas. Se essa caracterização estiver correta, então parece que, de fato, não há como escaparmos da objeção de Jackson (1982).

É importante lembrarmos, no entanto, que se a caracterização da Ciência Cognitiva que apresentei aqui é uma caracterização plausível, então nós não devemos nos preocupar com este tipo de objeção uma vez que esta é uma objeção feita a apenas um domínio ontológico em específico. Mais especificamente, esta é uma concepção de qualia característica do nível pessoal de análise. Tentei mostrar, entretanto, que não devemos nos restringir somente a este nível quando pretendemos estudar a mente ${ }^{11}$.

Na nossa discussão das teorias "interfield", vimos que uma compreensão plena dos qualia deve ser dada não somente por estudos na psicologia (nível pessoal), mas também por estudos na neurociência (nível sub-pessoal) e outras áreas de investigação como a biologia evolutiva. Tendo em vista esta perspectiva, cabe-nos lembrar aqui que um dos principais aspectos das teorias “interfield” de Darden e Maull (1977) é que as várias áreas de investigações envolvidas em uma teoria "interfield" devem proporcionar respostas para questões que parecem insolúveis ou muito difíceis de serem resolvidas com os conceitos e a metodologia do domínio ao qual estas questões pertencem. Nesse sentido, se levarmos em conta os esforços interdisciplinares previstos pelas teorias "interfield" e pela Ciência Cognitiva, então as análises no nível sub-pessoal podem nos ajudar a lidar com dificuldades apresentadas no nível pessoal.

Neste contexto, parece estar claro que uma vez que consideremos os qualia a partir do nível sub-pessoal de análise, as dificuldades associadas com as três características metafísicas

\footnotetext{
${ }^{11}$ Outros filósofos como Paul Churhcland (1989), David Lewis (1988) e Laurence Nemirow (1988) apresentam outras dificuldades em relação ao argumento de Jackson (1982). Para eles, há uma ambigüidade no uso do verbo "conhecer" (to know) nas premissas do argumento de Jackson. Lewis e Nemirow, por exemplo, defendem que Mary não sabe como é ver algo vermelho porque ela não tem certas habilidades, a saber, a habilidade de reconhecer algo vermelho, de lembrar de algo vermelho, etc.
} 
tradicionais de qualia podem ser postas em questionamento. Isso quer dizer que quando consideramos o estudo dos qualia a partir das pressuposições de uma teoria "interfield", a plausibilidade da conclusão dos argumentos de Jackson (1982) e Nagel (1974) pode ser questionada uma vez que uma das características essenciais das teorias "interfield" é a de que descobertas e experimentos em uma área de investigação ajudam a resolver problemas aparentemente insolúveis em outras áreas.

Assim, se pretendemos estudar os qualia a partir das teorias "interfield", o que espero ter demonstrado ser um caminho promissor, então não precisamos nos preocupar com as duas objeções das quais tratamos aqui, a saber, as objeções de Jackson (1982) e Nagel (1974), uma vez que descobertas em uma área de investigação irão eventualmente lançar luzes sobre as dificuldades apresentadas em outra área. Disso se segue que os argumentos de Jackson (1982) e Nagel (1974) não devem ser considerados como objeções a priori a um materialismo que está fundamentado nas teorias "interfield", já que as dificuldades encontradas pela psicologia podem ser endereçadas pela neurociência e outras áreas. 


\section{Referências}

CHURCHLAND, P. M. Eliminative materialism and the propositional attitudes. In: The Journal of Philosophy, 78: 67-90, 1981.

. (1989). Knowing Qualia: A Reply to Jackson. In: CHURCHLAND, P. M;

CHURCHLAND, P. S. On the Contrary. Cambridge: MIT Press, 1998.

DARDEN, L. e MAULL, N. (1977) Interfield theories. In: DARDEN, L. (Org.). Reasoning in Biological Discoveries. Cambridge: Cambridge University Press, 2006.

DENNETT, D. (1969). Content and Consciousness. New York: Routledge, 1996.

DENNETT, D. (1981). Three kinds of intentional psychology. In: DENNETT, D. The Intentional Stance. Cambridge: MIT Press, 1987.

. (1988) Quining Qualia. CHALMERS, D. (Org.). Philosophy of Mind Classical and Contemporary Readings. New York: Oxford University Press, 2002. . (1991). Consciousness Explained. London: Penguin Books, 1993.

GARDNER, H. (1987). The mind's new science. Basic Books, 1987.

JACKSON, F. Epiphenomenal qualia. In: Philosophical Quarterly, 32: 127-136, 1982.

. What Mary didn't know. In: Journal of Philosophy, 83: 291-5, 1986.

KOLAK, D.; HIRSTEIN, W.; MANDIK, P.; WASKAN, J. Cognitive science: an introduction to mind and brain. New York: Routledge, 2006.

LEWIS, D. (1988). What experience teaches. In: CHALMERS, D. (Org.). Philosophy of Mind Classical and Contemporary Readings. New York: Oxford University Press, 2002.

MCCAULEY, R. and BECHTEL, W. Explanatory Pluralism and Heuristic Identity Theory. In Theory and Psychology, 11: 736-60, 2001. 
Poderá a ciência cognitiva explicar os aspectos qualitativos de nossos estados mentais?

NEMIROW, L. (1988). Physicalism and the cognitive role of acquaintance. In: LYCAN, W. (Org.). (1988). Mind and cognition: an anthology. Oxford: Blackwell, 1988.

NAGEL, T. (1974). What is it like to be a bat? In: Philosophical Review, 83: 435-456, 1974.

STILLING, N.; WEISLER, S.; CHASE, C.; FEINSTEIN, M.; GARFIELD, J. e RISSLAND, E. (1995). Cognitive science: an introduction. 2nd Edition. Cambridge: MIT Press, 1995. 